\title{
Digital Object Identifier (DOI): o que é, para que serve, como
} se usa?

\section{Digital Object Identifier (DOI): what is it, how does it work and how to use it?}

Elisabete Ferreira ${ }^{1}$, Fabiane Führ ${ }^{2}$, Karolayne Costa Rodrigues de Lima ${ }^{1}$, Paula Carina de Araújo ${ }^{3}$, Suzana Zulpo Pereira $^{1}$

1 Universidade Federal do Paraná - UFPR, Brasil

2 Universidade Federal do Paraná - UFPR. Universidade Tuiuti do Paraná - UTP, Brasil

${ }^{3}$ Universidade Federal do Paraná - UFPR. Universidade Estadual Júlio de Mesquita Filho - UNESP, Brasil

Autor para correspondência/Mail to: Paula Carina de Araújo paula.carina.a@gmail.com

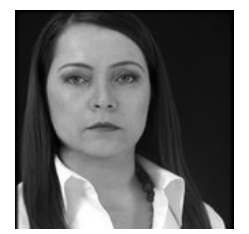

Elisabete Ferreira Bacharel em Processamento de Dados - FACET. Mestranda em Ciência da Computação - UFPR. Analista de Tecnologia da Informação do SIBI/UFPR. Membro da equipe de gestão do Repositório Digital Institucional UFPR.

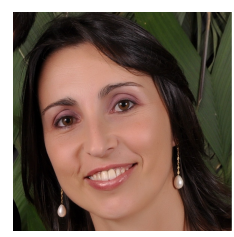

Fabiane Führ Bacharel em Biblioteconomia - Habilitação em Gestão da Informação - UDESC. Especialista em Gerenciamento de Projetos - Faculdade de Tecnologia/SENAC. Mestranda em Comunicação e Linguagens - UTP. Bibliotecária do SIBI/UFPR. Membro da equipe de gestão do Repositório Digital Institucional - UFPR.

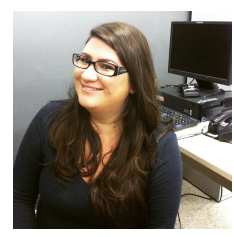

Karolayne Costa Rodrigues de Lima Bacharel em Biblioteconomia - Habilitação em Gestão da Informação - UDESC. Especialista em Gestão Pública - IFPR. Bibliotecária do SIBI/UFPR - Chefe da Biblioteca campus Cabral/Batel. Vicecoordenadora do Repositório Digital Institucional - UFPR.

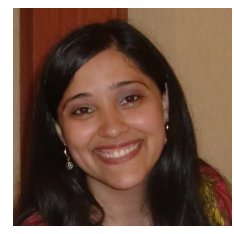

Paula Carina de Araújo Bacharel em Biblioteconomia - Habilitação em Gestão da Informação - UDESC. Mestre em Ciência, Gestão e Tecnologia da Informação - UFPR. Doutoranda em Ciência da Informação UNESP/Marília. Docente do Curso de Biblioteconomia a distância - UCS. Coordenadora da Biblioteca de Ciências Jurídicas - UFPR. Membro da equipe de gestão do Repositório Digital Institucional - UFPR.

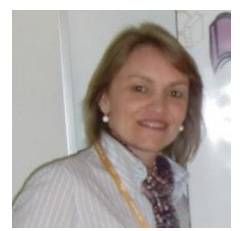

Suzana Zulpo Pereira Bacharel em Biblioteconomia - Habilitação em Gestão da Informação - UDESC. Especialista em Gestão Estratégica - UFPR. Bibliotecária do SiBi/UFPR. Chefe da Coordenação da Coleção Memória da MUFPR/UFPR. Membro da equipe de gestão do Repositório Digital Institucional - UFPR.

Agradecimentos/Acknowledgments: A Equipe Editorial da AtoZ agradece os autores, leitores, avaliadores e demais colaboradores que participaram na elaboração das questões para esta entrevista.

Copyright (c) 2015 Ferreira et al.. Todo o conteúdo da Revista (incluindo-se instruções, política editorial e modelos) está sob uma licença Creative Commons Atribuição-NãoComercial-Compartilhalgual 3.0 Não Adaptada. Ao serem publicados por esta Revista, os artigos são de livre uso em ambientes educacionais, de pesquisa e não comerciais, com atribuição de autoria obrigatória. Mais informações em http://ojs.c3sl.ufpr.br/ojs2/index.php/atoz/about/submissions\#copyrightNotice.

\section{Resumo}

Membros da equipe de gestão da Biblioteca Digital de Periódicos (BDP) da Universidade Federal do Paraná (UFPR) apresentam conceitos e esclarecem as principais dúvidas sobre o Digital Object Identifier (DOI).

Palavras-chave: Digital Object Identifier; Identificador persistente; Repositórios digitais

\author{
Abstract \\ The members of the management team of the Digital Library of Academic Journals (BDP) of the Federal University of Parana (UFPR) presents the main \\ concepts and clarify questions about the Digital Object Identifier (DOI).
}

Keywords: Digital Object Identifier (DOI); Persistent identifier; digital repositories 


\section{O QUE É O DOI E QUAL SUA RELAÇÃO COM O CROSSREF?}

DOI significa Digital Object Identifier, ou seja, Identificador de Objeto Digital. É um padrão para identificação de documentos em redes digitais. Composto por números e letras, é atribuído a um objeto digital para que este seja identificado de forma única e persistente no ambiente Web. O DOI originou-se de uma iniciativa conjunta de três associações comerciais na indústria editorial (International Publishers Association; International Association of Scientific, Technical and Medical Publishers; e Association of American Publishers) como uma estrutura genérica para a gestão de identificação de conteúdos através de redes digitais, considerando a tendência para a convergência digital e a crescente disponibilidade de multimídias (International DOI Foundation, 2014). A CrossRef é uma associação de editores e instituições que publicam na internet e que necessitam registrar seu conteúdo e metadados de forma única e persistente. Ela é o principal agente de atribuições de DOIs no mundo (Damásio, 2013).

\section{O DOI É APLICÁVEL APENAS PARA ARTIGOS CIENTÍFICOS?}

Não. O DOI pode ser aplicado a qualquer objeto digital (livros, capítulos de livros, periódicos, artigos etc.).

\section{QUAIS SÃO OS ERROS MAIS COMUNS DE PREENCHIMENTO DO DOI NO CURRÍCULO LATTES?}

Os principais erros para o preenchimento do DOI no Currículo Lattes são:

a) erros e/ou incompletudes no preenchimento dos metadados referentes ao nome do(s) autor(s) no periódico, por parte dos autores na hora da submissão e da equipe editorial na revisão;

b) incoerências entre o nome do autor cadastrado na Plataforma Lattes e na publicação que recebeu o DOI;

c) erro na inserção do DOI na Plataforma Lattes, pois os autores inserem, por exemplo, o endereço completo http://dx.doi.org/10.1590/S0100-39842002000100015, quando o correto é inserir dessa forma:

10.1590/S0100-39842002000100015.

\section{UMA PESSOA FÍSICA (O AUTOR) PODE SOLICITAR O DOI DE MANEIRA DIRETA?}

Não. Uma pessoa física deve entrar em contato com uma das Agências de Filiação disponível na página da CrossRef (http://www.crossref.org/).

\section{QUAIS SÃO OS CRITÉRIOS E REQUISITOS PARA A ASSOCIAÇÃO E PERMANÊNCIA NA CROSSREF?}

É necessário se associar à Publishers Association Linking Internacional (PILA), organização sem fins lucrativos que analisa e aprova os pedidos de adesão à CrossRef. Após a aprovação do pedido e pagamento da taxa anual de associação, o prefixo e demais informações para o acesso e atribuição dos DOIs serão fornecidos, sendo que todo o processo de associação e atribuição é realizado em inglês e todas as taxas são pagas em dólar.

Segundo informações obtidas no site da CrossRef (2015), devem ser seguidas as seguintes regras:

a) os afiliados devem assinar e respeitar o Acordo de Afiliação da CrossRef;

b) os afiliados devem pagar as taxas listadas na Tabela de Taxas da CrossRef;

c) a taxa administrativa anual é baseada na maior receita anual de negócios da organização filiada;

d) não há taxas de recuperação por DOI e não há taxas com base no número de links criados com o DOIs;

e) afiliados podem recuperar DOIs (ou seja, armazená-los em seus sistemas locais);

f) o proprietário dos direitos autorais de uma publicação é o único com autoridade para designar ou autorizar um agente para designar, depositar e resolver as URLs para o conteúdo que aparece na publicação;

g) um periódico - se está hospedado pelo editor ou incluído em um serviço agregador ou banco de dados- deve ser depositado no sistema CrossRef antes de membros ou afiliados da CrossRef tentarem a recuperação dos DOIs dos artigos. Por exemplo, um membro que hospeda artigos em texto completo só pode pesquisar DOIs se o editor da revista que é membro da PILA realizar o depósito dos metadados para a revista no sistema CrossRef; (veja mais em: http://www.crossref.org/04intermediaries/60affiliate_rules.html). 
Entretanto, em 18 de dezembro de 2014 foi estabelecido um acordo entre a Associação Brasileira de Editores Científicos (ABEC), CrossRef e Instituto Brasileiro de Informação em Ciência e Tecnologia (IBICT) que irá facilitar o processo para depósito de DOIs da produção científica das instituições brasileiras. Neste acordo, a ABEC assume o papel de Sponsoring entity e o IBICT o de suporte técnico. A partir de então, a ABEC é responsável pelo pagamento da anuidade de afiliação à CrossRef em nome de todas as instituições brasileiras que optarem pela representação, desde que classificadas como instituições ou associações não comerciais e sem fins lucrativos. As instituições permanecerão membros da CrossRef e terão todos seus direitos e deveres mantidos, além disso, o processo de atribuição de DOIs em si, não sofrerá nenhuma alteração. As instituições continuarão atribuindo DOIs às suas publicações de forma independente e usando o prefixo já definido. A novidade está no pagamento, pois a CrossRef enviará a fatura diretamente para a ABEC, que repassará a cobrança para cada instituição. Essa intermediação, realizada pela $\mathrm{ABEC}$, irá acabar com a necessidade de envio de recursos para o exterior. As instituições que já eram associadas à PILA/CrossRef podem fazer um acordo indicando a ABEC como sua representante por meio do termo Represented Member Agreement e as instituições ainda não filiadas podem solicitar o mesmo termo que irá servir tanto para fins de associação, como para representação. (Associação Brasileira de Editores Científicos (ABEC), 2014). Demais informações sobre o acordo estabelecido entre ABEC, CrossRef e IBICT podem ser consultadas em:http://www.abecbrasil.org.br/.

\section{6. É POSSÍVEL MENSURAR O RETORNO DO INVESTIMENTO DE UMA INSTITUIÇÃO QUE ATRIBUI O DOI ÀS SUAS PUBLICAÇÕES?}

O principal retorno para as instituições que atribuem DOI às suas publicações é o acesso, a disponibilidade de metadados e a visibilidade, pois a atribuição dos identificadores persistentes garante que um mesmo documento possa ser rearranjado na Web sem a perda de seu acesso. Além disso, é possível integrar todos os formatos de dados (PDF, HTML, entre outras) para que recebam o mesmo número de identificador persistente garantindo que todos os documentos sejam localizados de maneira única.

Outra forma de obter retorno do investimento é a utilização do mesmo DOI em diferentes plataformas, como por exemplo, na Plataforma Lattes do Conselho Nacional de Desenvolvimento Científico e Tecnológico (CNPq) que utiliza as informações do DOI como uma forma de certificação digital da produção científica dos pesquisadores por meio do Currículo Lattes.

\section{O DOI PODE SER CONSIDERADO COMO UMA BASE DE DADOS INDEXADORA DE CONTEÚDO CIENTÍFICO? POR QUÊ?}

Não. Conforme citado anteriormente, o DOI é uma aplicação voltada para "a identificação persistente de recursos digitais sobre os quais possam ser atribuídos direitos de propriedade intelectual, bem como para o intercâmbio de informações sobre essas propriedades em um ambiente de rede” (Sayão, 2007, p. 73). Cabe ainda destacar que o DOI também "associa aos objetos digitais dados estruturados - informações bibliográficas e comerciais atualizáveis” (Sayão, 2007, p. 73).

Os metadados dos objetos digitais que recebem o DOI são disponibilizados para busca por meio da base de dados CrossRef Metadada Search. Entretanto, essa base de dados também não é considerada indexadora, pois não gera nenhum tipo de indicador bibliométrico (indicador de produção, citação e/ou colaboração) como fazem a Web of Science e a Scopus, por exemplo.

\section{O DOI EXCLUI A PREOCUPAÇÃO DAS REVISTAS/REPOSITÓRIOS COM RELAÇÃO ÀS POLÍTICAS DE PRESERVAÇÃO? POR QUÊ?}

O DOI garante o acesso e localização dos metadados do objeto digital, mas somente ele não é suficiente para excluir a preocupação em relação à preservação do que é publicado no ambiente digital. É necessário o estabelecimento de políticas e diretrizes que norteiem o processo de preservação digital, definição de critérios de seleção do que será preservado e como será armazenado.

Uma das estratégias sugeridas na literatura é que as instituições tenham repositórios digitais confiáveis, com políticas claras que assegurem tanto o acesso como a preservação dos objetos digitais.

A Carta para Preservação do Patrimônio Arquivístico Digital da UNESCO de 2003 é uma das principais iniciativas mundiais para a preservação digital. Nela são definidas cinco características para a elaboração de um programa de preservação digital: responsabilidade, viabilidade organizacional, sustentabilidade, adequação técnica, segurança e responsabilização de procedimentos (Silva Júnior \& Mota, 2012). 


\section{UMA DAS VANTAGENS DO DOI É A CRIAÇÃO DE HIPERLINKS (CONEXÕES) ENTRE DO- CUMENTOS. NESTE MOMENTO, EM QUE A ABNT AINDA NÃO CONTEMPLA UMA DIRE- TRIZ ESPECÍFICA SOBRE A INDICAÇÃO DO DOI, COMO OS EDITORES PODERIAM ORI- ENTAR OS AUTORES NA ELABORAÇÃO DE REFERÊNCIAS/CITAÇÕES, POR EXEMPLO?}

A norma da ABNT, em vigência, NBR 6023 de 2002 sugere que, para os documentos acessados online, seja acrescido ao final da referência a informação de "Disponível em:" seguida da URL entre os sinais < >, acrescida de "Acesso em:" e indicação da data de acesso. É importante destacar que, nesse caso, a indicação da data de acesso é muito importante tendo em vista que a URL não é um link persistente e pode, a qualquer momento, perder o acesso ao documento (Associação Brasileira de Normas Técnicas (ABNT), 2002).

Podem ser citados dois exemplos diferentes de como vem sendo citado o DOI nas referências, tendo em vista que sua indicação é muito importante para a criação das conexões entre os documentos.

O SciELO disponibiliza a ferramenta How to cite this article para todos os seus artigos, e insere o DOI após a indicação de data de acesso do documento para referências seguindo a NBR 6023 de 2002, conforme exemplo abaixo:

KOTSUBO, Martha Tidori Kiota; MARCHIORI, Edson; AZEVEDO, Ana Cecília P.. Radiografia de tórax: avaliação da qualidade de imagem, doses e custos. Radiologia Brasileira, São Paulo , v. 35, n. 1, p. 26, 2002. Disponível em: <http://www.scielo.br/scielo.php?script=sci_arttext\&pid=S0100-39842002000100015\&lng=en\&nrm=iso>. Acesso em: 16 jul. 2015. http://dx.doi.org/10.1590/S0100-39842002000100015.

Já a norma de Vancouver sugere a substituição da URL e a data de acesso pelo DOI (Universidade de São Paulo (USP). Sistema Integrado de Bibliotecas, 2009). Esta opção parece mais coerente, tendo em vista que a data de acesso não é mais imprescindível, uma vez que, por ser um link persistente o DOI continuará o mesmo independente da mudança de servidor. Segue o exemplo:

Kotsubo M. T. K., Marchiori E., Azevedo A. C. P.. Radiografia de tórax: avaliação da qualidade de imagem, doses e custos. Radiologia Brasileira. 2002; 35 (1):26-26. doi:10.1590/S0100-39842002000100015. 


\section{REFERÊNCIAS}

Associação Brasileira de Editores Científicos (ABEC). (2014). Estabelecido o acordo ABEC/CROSSREF/IBICT para facilitar a atribuição de DOIs. Recuperado em 06 jun. 2015, de http:// www.abecbrasil.org.br/index.asp

Associação Brasileira de Normas Técnicas (ABNT). (2002). NBR 6023: informação e documentação: referências: elaboração. Rio de Janeiro.

CrossRef. (2015). Affiliate rules. Recuperado em 16 jul. 2015, de http://www.crossref.org/04intermediaries/ 60affiliate_rules.html

Damásio, E. (2013). Crossref, DOI (Digital Object Identifier) e serviços: estudo comparativo luso-brasileiro. InCID: $R e-$ vista de Ciência da Informação e Documentação, 4(4), 126-142. Recuperado em 15 jul. 2015, de http://www.revistas.usp.br/ incid/article/view/69305

International DOI Foundation. (2014). DOI handbook. Recuperado em 10 jul. 2015, de http://www.doi.org/hb.html

Sayão, L. F. (2007). Interoperabilidade das bibliotecas digitais: o papel dos sistemas de indentificados persistentes - URN, PURL, DOI, Handle System, CrossRef e Open URL. Transinformação, 19(1), 65-82. Recuperado em 13 ago. 2015, de http://dx.doi.org/10.1590/S0103-37862007000100006

Silva Júnior, L. P., \& Mota, V. G. (2012). Políticas de preservação digital no Brasil: características e implementações. Ciência da Informação, 41(1), 51-64. Recuperado em 13 ago. 2015, de http://revista.ibict.br/ciinf/index.php/ciinf/article/ view/2123/1806

Universidade de São Paulo (USP). Sistema Integrado de Bibliotecas. (2009). Diretrizes para apresentação de dissertações e teses da USP: documento eletrônico e impresso: parte IV (Vancouver). São Paulo: USP. Recuperado em 13 ago. 2015, de http://www.teses.usp.br/index.php?option= com_content \&view=article \&id=52 \&Itemid=67

\section{Como citar esta entrevista (APA):}

Ferreira, E., Führ, F., Lima, K. C. R., Araújo, P. C. \& Pereira, S. Z. (2015). Digital Object Identifier (DOI): o que é, para que serve, como se usa?. AtoZ: novas práticas em informação e conhecimento, 4(1), 5 - 9. Recuperado de: http://dx.doi.org/10.5380/atoz.v4i1.42369 